\title{
LOS MACHOS ESTÁN CANSADOS ${ }^{1}$
}

\author{
Jean-Jacques Courtine \\ Université Sorbonne Nouvelle/Paris III, Paris, França
}

El 17 de julio de 2012 Cécile Duflot, Ministra de Igualdad de Territorios y Vivienda, desciende las gradas de la Asamblea Nacional y se acerca al micrófono. En las bancas de la derecha parlamentaria, estallaron los abucheos. La ministra tenía puesto un vestido de flores... ${ }^{2}$. Unos días más tarde, una estudiante belga, hastiada de las injurias sexistas que escanden sus paseos por la ciudad, las registra con una cámara oculta. ${ }^{3}$ Ambos incidentes fueron inmediatamente condenados en los medios de comunicación, en términos rigurosamente semejantes: el mismo viento de "machismo cotidiano", "tonto", incluso "troglodita" (El observador del 22 de julio de 2012) sopla sobre el Palais-Bourbon y en las calles de Bruselas. En este inicio de siglo XXI, el machismo tiene, sin dudas, mala prensa. Ninguna palabra parece suficientemente fuerte para estigmatizar el resurgimiento de la dominación masculina bajo su forma más arcaica, nacida antiguamente en los alrededores de la cuenca mediterránea.

Esto no resulta, no obstante, tan simple: si es cierto que se desaprueban tales comportamientos, llama la atención la unanimidad de los términos con los cuales se formula su rechazo. El asunto, así planteado, nos da una buena ocasión para hacer un breve recorrido antropológico e histórico sobre el machismo de hoy en día, y sobre el lugar que debemos otorgarle en "el gran bazar del género". Que sus orígenes sean fuertemente lejanos no genera ninguna duda, que su carácter sea esencialmente mediterráneo es cierto si observamos la etimología, pero desde un punto de vista antropológico es

\footnotetext{
1 Texto originalmente publicado em: Courtine, Jean-Jacques. "Les machos sont fatigués ". In.: D. Chevallier, M. Bozon, M. Perrot, \& F. Rochefort (Eds.). Le bazar du genre. Marseille: MUCEM. 2013. p. 119-125.

Tradução de Mara Glozman.

2 En una Asamblea con un $27 \%$ de mujeres -dato que hizo recientemente ascender a Francia, en materia de paridad, del puesto 69 al 34 en el ranking mundial, entre Tunes y Afganistán-, ¿esto realmente constituye una sorpresa?
}

3 Sofie Peeters, Mujer de la calle, film documental, 2012. 
preciso tener mayor cautela: considerar que el machismo pertenece al pasado y que solo retorna en nuestra actualidad bajo una forma fosilizada sería desconocer su extrema resiliencia y sus múltiples reinvenciones. Finalmente, es evidente que forma parte del arsenal de la dominación masculina, pero no es seguro que en la actualidad sea su arma esencial ni que las mujeres sean sus únicas víctimas; ni siquiera, tal vez, sea tan seguro que se dirija esencialmente a ellas.

\section{Antigüedad: los fundamentos del machismo mediterráneo}

No hay duda de que el machismo en el Mediterráneo tiene orígenes arcaicos y una larga memoria; tampoco hay duda de que se inscriba en una concepción "natural" de la dominación masculina. Así, cuando Aristóteles, entre 330 y 322 a.C., tiene que explicar en su texto Reproducción de los animales la reproducción de la especie humana, las cosas se presentan, al fin y al cabo, de una manera bastante simple: el macho es caliente y activo; la hembra, fría y pasiva. El machismo mediterráneo se inaugura, en el mundo griego antiguo, bajo la forma de una teoría imaginaria de la procreación ideal. La potencia masculina es su principio esencial, y, cuando la potencia masculina domina, sabrá reproducir hombres que se asemejen a sus padres: el nascimiento de hijas no es más que un fracaso para la reproducción. El "machismo arcaico", si es que debemos llamarlo así, se obnubila en un comienzo con la reproducción de los hombres por ellos mismos; esto es justamente lo que les prohíbe la naturaleza: una respuesta al exorbitante privilegio femenino del parto (véase NADALINI, 2013; CID LÓPEZ, 2013). El modelo griego es, desde este punto de vista, perfectamente coherente, y desde la epopeya homérica toda la sociedad queda organizada en torno al macho adulto (FINLEY, 1995): las mujeres pueden perfectamente seguir dando a luz mientras los hombres se ocupan de producir héroes. La sociedad antigua, griega y luego romana, se caracteriza por una búsqueda y una jerarquización obsesivas del honor guerrero, y la dominación masculina en el mundo mediterráneo -sea este cristiano, musulmán o judío- conservará durante mucho tiempo el trazo de esta obsesión primera, en el seno de culturas que, nos parece, comparten tres grandes series de rasgos.

En primer lugar, tales culturas se fundan sobre una concepción del honor basada en las formas tradicionales de afirmación de la virilidad -fuerza, agresividad, coraje, potencia sexual y fecundante: ¿̨no dice, acaso, 
un proverbio cabilio ${ }^{4}$ que el pene es el único macho que puede incubar dos huevos? (BOURDIEU, 2000, p. 25). En segundo lugar, las culturas mediterráneas están fundadas en la pertenencia a una familia patriarcal y autoritaria, y en la capacidad de afrontar un reto en su nombre ("El punto de honor (nif), dice Bourdieu a propósito de la sociedad cabilia, "es la base del código moral de un individuo que se ve a sí mismo solamente a través de los ojos de los demás, porque la imagen que tiene de sí mismo es indistinguible de la que le presentan los otros" (BOURDIEU, 1965, p. 211)). En tercer y último lugar, son culturas que se sustentan en el control a las mujeres, tanto a aquellas que se desprecia como a aquellas que son veneradas: uso sexual de unas pero demanda de castidad para las otras, madres y hermanas, fuentes y medidas fetichizadas del honor de los hombres -pero también de su vergüenza y de su vulnerabilidad-, objetos de una protección celosa, en ocasiones de un verdadero culto (así dice Albert Cohen: "Las saludo, madres llenas de gracia, santas centinelas, coraje y bondad, calidez y mirada de amor [...], ustedes, únicos seres humanos en los que podemos confiar y que nunca, nunca, nos traicionarán” (1992, p. 114)).

\section{Las transformaciones contemporáneas}

El honor y la vergüenza; la familia y los otros; la mamá y la puta. He aquí, sin dudas, lo que el machismo de los orígenes recibió en su cuna. La antropología de los mundos bíblico, griego, romano y musulmán confirma la extensión de estas representaciones a los antiguos cimientos mediterráneos, y más allá (PITT-RIVERS, 1954; PERISTIANY, 1995; GILMORE, 1987; PERISTIANY; PITT-RIVERS, 1992). La historia de la virilidad muestra hasta qué punto el machismo ha sabido atravesar los siglos y conservar durante mucho tiempo sus rasgos esenciales, ultrapasando las transformaciones históricas: después de todo, el duelo -una de las formas de expresión del machismo más puras- ha experimentado una enorme expansión en Francia en la segunda mitad del siglo XIX (CORBIN; COURTINE; VIGARELLO, 2011). En el duelo aún se mata y se muere para defender el honor.

Este modelo de virilidad machista, cuya ambición era encarnar el

\footnotetext{
${ }^{4}$ Lengua y sociedad bereber, región del norte de Argelia. Las formulaciones de Pierre Bourdieu sobre las relaciones de género en la sociedad cabilia tienen un papel relevante en sus análisis acerca de "la dominación masculina" [Nota de traducción].
} 
fundamento natural y eterno de la dominación masculina, ha perdido poco a poco su fuerza y su crédito en el Occidente contemporáneo, y solamente es posible encontrar sus formas primitivas, en estado fosilizado, dentro de la contracultura de grupos masculinos cerrados: fraternidades, pandillas y bandas, mafias... Pero conviene no olvidar su extrema resiliencia y sus múltiples reinvenciones en la sociedad de masas globalizada que es, hoy en día, la nuestra. Arrancado de sus raíces arcaicas, indudablemente el machismo se ha debilitado; aun así, no debe subestimarse la violencia que continúa encarnando. Especialmente, se ha diseminado, metamorfoseado, desplazado y relocalizado en el mercado "líquido" y mundializado de las mercaderías y las transferencias culturales: "la visión "falonarcisista» y de la cosmología androcéntrica que comparten todas las sociedades mediterráneas [...] sigue sobreviviendo, en estado parcial y como fragmentado, en nuestras estructuras cognitivas y en nuestras estructuras sociales" (BOURDIEU, 2000, p. 18).

Echemos rápidamente un vistazo a la historia del machismo en el transcurso del siglo que acaba de finalizar: esta sigue la historia, más general, de la virilidad, que constituye su corazón y su principio. Ahora bien, la historia de la virilidad fue, en las sociedades mediterráneas desde fines del siglo XIX, el teatro de una crisis endémica que pareciera haber alcanzado su apogeo con la Primera Guerra Mundial. La virilidad, ciertamente, se ha reunido con la muerte desde sus orígenes, pero en la Gran Guerra la devastación de los cuerpos masculinos adquirió tal magnitud que el mito viril fue, literalmente, amputado. La Segunda Guerra Mundial, y luego las últimas guerras coloniales, terminaron de dar fin, en Occidente, al entusiasmo viril por la proeza militar y pusieron un límite a la búsqueda heroica del honor guerrero. Una nueva crisis, esta vez en el frente del trabajo, acontece en el período de entreguerras, que ve el despojo del trabajador por los continuos avances del maquinismo, su descalificación por el desempleo durante la depresión de los años ' 30 y, más en general, lo que se siente como una disminución de las energías viriles por el aumento de los conformismos y de la burocracia en la sociedad urbana de masas.

\section{El macho de América Latina}

¿El machismo parece ser más adecuado para las pequeñas sociedades locales y rurales en el antiguo Mediterráneo que para las metrópolis industrializadas y cosmopolitas de la modernidad? Diríamos esto solo si 
no tuviéramos en tener en cuenta la asombrosa propensión de los mitos a recrear el origen, especialmente cuando se trata de hablar sobre la primera naturaleza del hombre: al quedarse sin aire en su tierra natal, el machismo se reinventará en otro lugar, hasta el punto de que este segundo nacimiento hoy en día parece tener tanta legitimidad como el primero. El macho es ahora igual, o quizás aún más, latinoamericano que, propiamente hablando, mediterráneo.

Ejemplo de ello es el caso argentino, que pone de relieve las condiciones de este renacimiento. Desde el final del siglo XIX hasta las primeras décadas del XX, Argentina se inscribe plenamente en el mercado capitalista mundial, al mismo tiempo que experimenta una inmigración masiva, una urbanización acelerada y nuevas formas de consumo de productos culturales masivos. Buenos Aires deviene la Babel cosmopolita. Pero la absorción de estas oleadas de inmigración provenientes de Europa requiere una redefinición de la identidad nacional basada en un Estado que garantice los valores viriles de orden y disciplina. Es entonces cuando aparece el macho argentino, con los tonos del tango: la asociación del tango, producto cultural urbano moderno, y el atuendo del gaucho de la pampa, asociado al pasado rural de la nación, ofrece un modelo viril a la resolución imaginaria de las contradicciones de la identidad nacional (ARCHETTI, 2007, p. 212-229). El macho argentino acaba de nacer en una reinvención de la tradición, en el mismo momento, precisamente, en que los gauchos reales están desapareciendo de los campos. Es una propiedad del machismo, y de la virilidad en general, resucitar de esta manera cuando los creemos disipados, nuevamente revestidos con los fetiches de la potencia que portaban los hombres de ayer. El machismo es una nostalgia, el duelo interminable de una potencia masculina que se siente amenazada o perdida, y es la brutalidad rural de la pampa la que convoca al bandoneón y a la voz de Gardel en el corazón de la cosmopolita vida urbana de Buenos Aires. Pero el macho, una vez reinventado, abandona su segunda patria, y regresa, extrańo destino, a la misma tierra de sus orígenes lejanos: la globalización precoz de las mercancías culturales permite la recepción del tango en Europa -especialmente en París- e impulsa, así, al macho de segunda generación a una circulación casi universal del estereotipo.

El ejemplo mexicano, mutatis mutandis, lo confirma. Una vez más, la nostalgia es la regla. En los fondos de la Colonia Santo Domingo, uno de esos barrios populares de la ciudad de México donde fueron concebidas las variantes locales del machismo, hoy en día, "el machismo lleva en él un cierto elemento de nostalgia; es cultivado por aquellos que tienen el sentimiento de haber nacido demasiado tarde" (GUTMANN, 1996, p. 
227). Allí también, como en Argentina, el macho fue reinventado: el pelado grosero y brutal, surgido de la plebe, dará paso al héroe de la revolución mexicana, encarnación viril del pueblo y de la patria. Esta vez no son los tonos del tango, sino el cine nacionalista mexicano de los años 1930 y 1940 lo que pondrá al estereotipo del macho mexicano en órbita planetaria. Y, también en este caso, será necesario que "la fábrica de sueńos" situada del otro lado de la frontera se lo apropie: la película ;Viva Zapata! de Kazán (1952) probablemente hizo más para globalizar el machismo mexicano que el propio Pancho Villa. Una sombra, sin embargo, planea ya sobre estos cantos a la gloria de una masculinidad triunfante, que presagia las desilusiones venideras. Octavio Paz ha sabido practicar la disección literaria de esta masculinidad en su Laberinto de la soledad (1950): es la vergüenza lo que hiere el orgullo del hombre mexicano, fruto de la violación de la mujer indígena por el conquistador extranjero.

\section{Machismo e igualdad entre los sexos}

La segunda mitad del siglo XX va a ser el momento histórico en el que, en el conjunto de Occidente, la virilidad se verá desafiada en sus privilegios más antiguos por el progreso de la igualdad entre los sexos y los avances del feminismo. La obtención por parte de las mujeres de nuevos derechos desde los años 1960 y 1970, el reajuste de los roles sexuados en las esferas pública y privada, el rechazo, y luego la condena, de la violencia contra el otro género: todo ello no ocurre sin socavar el edificio viril y avivar las angustias masculinas. Y todo ello acontece especialmente cuando se expande el dominio de la impotencia sexual, que -desde el principio del siglo, con la invención del psicoanálisis y, luego, la aparición de la sexología- ha dejado de ser asimilada a una simple falla mecánica para pasar a implicar un fracaso psicológico, en el cual toda la historia del sujeto está involucrada. Hasta que, en el viraje del siglo XXI, la hipermedicalización de las insuficiencias contribuye a crear, con la comercialización de prótesis químicas, un mercado de la impotencia. No es sorprendente semejante desbandada del machismo: basado "naturalmente" en la potencia masculina, siempre ha estado acompañado, como su lado oculto, por el temor a la vulnerabilidad corporal, la aprehensión de la falla sexual, la sombra del quiebre moral. "El privilegio masculino no deja de ser una trampa", recordaba Bourdieu, "una carga, [...] el principio de una inmensa vulnerabilidad" (BOURDIEU, 2000, p. 68-69). 
Una historia global de la dominación masculina debería, sin embargo, diferenciar las sociedades y los lugares donde prevalece la brutalidad machista de aquellos donde retrocede, incluso si las violencias sexuadas se hacen claramente presentes (VIRGILI, 2011) y donde se han inventado formas de dominación más indirectas o insidiosas, que preservan para el imperio del macho la mayor parte de los privilegios económicos y la autoridad política e institucional (DE SINGLY, 1993; GRÉSY, 2009; HAROCHE, 2011). Por eso es esencial no confundir, como suele hacerse, la dominación masculina y el machismo. Porque, fatigados por haber tenido que salvaguardar durante tanto tiempo las apariencias de virilidad, los machos parecen cansados en Occidente. La virilidad en sí parece disociarse, hoy en día, del cuerpo masculino, del que ha sido emblema durante tanto tiempo -mercancía, performance o travestismo, como ha sabido discernir Judith Butler (2018), y el machismo se restringe a la parte exhibida, teatral, emergente de la dominación masculina. Las representaciones contemporáneas del machismo lo dicen con suficiente claridad. A veces son del orden de la comedia, y le hacen el juego a lo ridículo, por ejemplo, encarnándose en el grotesco mediterráneo interpretado por Aldo Maccione en una serie de películas populares de la década de 1970. En otras ocasiones son del orden del sueño: separados de toda realidad masculina, las fantásticas evocaciones de cazadores primitivos, gladiadores antiguos o guerreros modernos se han convertido en los protagonistas de la dramaturgia eréctil y de las fantasías fálicas globalizadas. Tarzán, Conan, Rambo y los demás hacen sonar la carga de un fantasma que yacía en las pantallas de la cultura visual planetaria.

Finalmente, son del orden de la parodia: el alboroto machista de la Asamblea apuntaba solo incidentalmente a la ministra, y el vestido floral no era más que un pretexto. Los diputados de la derecha parlamentaria se dirigían, ante todo, unos a otros, porque el machismo es tanto un teatro de hombres como una forma de dominación sobre las mujeres. ¿Cómo resistir, ante el ojo de las cámaras, ante la irrupción del otro sexo en flor, el impulso arcaico de comulgar estruendosamente -de nuevo- en una parodia de este antiguo culto de dominación, que los hombres celebraban antiguamente? Una celebración entre ellos y dirigiéndose los unos a los otros. Esto no les impidió, ya disipado el aliento colectivo del calor machista, votar unos días más tarde, cada uno en su banca, la ley que condena el acoso sexual. Como un solo hombre.

\section{Referencias}


ARCHETTI, Eduardo P. Masculinity, Primitivism, and Power: Gaucho, Tango, and the Shaping of Argentine National Identity. In: FRENCH, W. E.; BLISS, K. E. (Dirs.). Gender, Sexuality, and Power in Latin America since Independence. Lanham: Rowman and Littlefield, 2007.

BOURDIEU, Pierre. La dominación masculina. Tradução Joaquín Jordá. Barcelona: Anagrama, 2000.

BOURDIEU, Pierre. The Sentiment of Honour in Kabyle Society. In: PERISTIANY, J. G. (Dir.) Honour and Shame: the Values of Mediterranean Society. Londres: Weidenfeld and Nicolson, 1965.

BUTLER, Judith. El género en disputa: el feminismo y la subversión de la identidad. Tradução María Antonia Muñoz. Buenos Aires: Paidós, 2018. CID LÓPEZ, Rosa María. Isis et la déesse-mére. In: CHEVALLIER, D.; BOZON, M.; PERROT, M.; F. ROCHEFORT (Orgs.) Au Bazar du Genre, Féminin/masculin en Méditerranée. Paris: MuCEM, 2013. p. 4952.

COHEN, Albert. El libro de mi madre. Tradução Javier Albiñana. Barcelona: Anagrama, 1992.

CORBIN, Alain; COURTINE, Jean-Jacques; VIGARELLO, Georges (Dirs.). Histoire de la virilité. Paris: Seuil, 2011.

DE SINGLY, François. Les Habits neufs de la domination masculine. Esprit, n. 11, p. 54-65, nov. 1993.

FINLEY, Moses I. El mundo de Odiseo. Tradução Mateo Hernández Barroso. Madrid: Fondo de Cultura Económica, 1995.

GILMORE, David (Dir.). Honor and Shame and the Unity of the Mediterranean. Arlington: American Anthropological Association, 1987.

GRÉSY, Brigitte. Petit traité contre le sexisme ordinaire. Paris: Albin Michel, 2009.

GUTMANN, Matthew C. The Meanings of Macho: Being a Man in Mexico City. Berkeley; Los Angeles; Londres: University of California Press, 1996.

HAROCHE, Claudine. Anthropologies de la virilité: la peur de l'impuissance. In: CORBIN, A.; COURTINE, J.-J.; G. VIGARELLO (Dirs.). Histoire de la virilité. Paris: Seuil, 2011. p. 15-30.

NADALINI, Eleonora. "L'homme enceint : du mythe a la réalité". In: CHEVAlLIER, D.; BOZON, M.; PERROT, M. ; ROCHEFORT, F. 
(Orgs.) Au bazar du genre : Féminin/masculin en Méditerranée. Paris: MuCEM, 2013. p. 74-75.

PERISTIANY, John G. (Dir.). Honour and Shame: the Values of Mediterranean Society. Londres: Weidenfeld and Nicolson, 1965.

PERISTIANY, John G.; Julian Pitt-Rivers (Dirs.). Honor and Grace in Anthropology. Cambridge: Cambridge University Press, 1992.

PITT-RIVERS, Julian. The People of the Sierra. Londres: Weidenfeld and Nicolson, 1954. 